\title{
Investigation of conductive hybrid polymer composites reinforced with copper micro fibers and carbon nanotubes produced by injection molding
}

Doagou-Rad, Saeed; Islam, Aminul; Antusch, Steffen; Jung, Judith; Klein, Alexander; Plewa, Klaus; Piotter, Volker

Published in:

Materials Today Communications

Link to article, DOI:

10.1016/j.mtcomm.2019.100566

Publication date:

2019

Document Version

Peer reviewed version

Link back to DTU Orbit

Citation (APA):

Doagou-Rad, S., Islam, A., Antusch, S., Jung, J., Klein, A., Plewa, K., \& Piotter, V. (2019). Investigation of conductive hybrid polymer composites reinforced with copper micro fibers and carbon nanotubes produced by injection molding. Materials Today Communications, 20, [100566].

https://doi.org/10.1016/j.mtcomm.2019.100566

\section{General rights}

Copyright and moral rights for the publications made accessible in the public portal are retained by the authors and/or other copyright owners and it is a condition of accessing publications that users recognise and abide by the legal requirements associated with these rights.

- Users may download and print one copy of any publication from the public portal for the purpose of private study or research.

- You may not further distribute the material or use it for any profit-making activity or commercial gain

- You may freely distribute the URL identifying the publication in the public portal 


\title{
Investigation of conductive hybrid polymer composites reinforced with copper micro fibers and carbon nanotubes produced by injection molding
}

\author{
Saeed Doagou-Rad ${ }^{\mathrm{a}, *}$, Aminul Islam ${ }^{\mathrm{a}}$, Steffen Antusch ${ }^{\mathrm{b}}$, Judith Jung ${ }^{\mathrm{b}}$, Alexander Klein ${ }^{\mathrm{b}}$, \\ Klaus Plewa ${ }^{\mathrm{b}}$, Volker Piotter ${ }^{\mathrm{b}}$ \\ a Department of Mechanical Engineering, Technical University of Denmark, Produktionstorvet, Building 427A, DK-2800, Kgs. Lyngby, Denmark \\ ${ }^{\mathrm{b}}$ Karlsruhe Institute of Technology (KIT), Institute for Applied Materials, 76344 Eggenstein-Leopoldshafen, Germany
}

\section{A R T I C L E I N F O}

\section{Keywords:}

Polymer-matrix composites (PMCs)

Electrical properties

Mechanical properties

Microstructures

Injection molding

\begin{abstract}
A B S T R A C T
Conductive polymeric composites have proved themselves invaluable for novel manufacturing and applications. In this paper, production and properties of injection moldable conductive plastics to replace metal circuits especially in micro components are investigated. Polymeric composites containing conductive micro and nano fillers are designed and characterized experimentally and numerically. Results show that hybridization of Copper micro fibers and carbon nanotubes enhances the conductivity properties two orders of magnitude while reducing the weight and cost of the composites. Moreover, the new injection moldable conductive plastics show improved mechanical and surface properties. The research endeavors to provide novel multifunctional solutions for future components with complex geometries.
\end{abstract}

\section{Introduction}

Conductive polymeric composites based on their level of electrical conductivities could be used for antistatic, electrostatic paintings, and electromagnetic interference shielding applications. Moreover, they are being used in different novel advanced applications such as sensors, damage monitoring, shape memory materials, thermoelectric materials, and printed electrical circuits [1-3]. The current trend towards continuous reduction of size, weight, and cost has led to search for the reduction of number of parts and assembly steps. This miniaturization in the area of micro components has changed the design aspects of the products towards complex geometries bound in limited spaces [4,5]. Therefore, reduction of the number of components and assembly steps is necessary in new productions. Conductive injection moldable plastic could be part of a solution since they are molded into complex geometries without the need for additional assembly steps. Recent advancements in technology demand for novel electrically and/or thermally conductive multifunctional plastics with the potential to be fabricated precisely, and through mass manufacturing processes. Incorporation of various conductive fillers such as metals fibers, carbon black, carbon fibers, and low melting alloys in the polymers to create a conductive network within a polymeric base has been one of the attempts toward this target [6-10].

While reducing the average distance between the fillers is desirable to achieve higher conductivities, increasing the content of these conventional conductive fillers within the polymeric system aftercertain volume contents leads to poor processibility, and degradation of other properties especially mechanical behaviors $[8,12]$. In fact, metallic fillers are traditionally considered as the prime candidates to achieve high levels of conductivity in plastics, however, their susceptibility to oxidation, corrosion, and high densities and costs are some of their major drawbacks. The advent of novel nanomaterials with their high conductivity and aspect ratios has provided new possibilities to extend the properties and applications [13-15]. Inclusion of conductive nanofillers in addition to enhancement of the primary desired conductivity properties could additionally increase other properties such as stiffness, hardness, damping, etc. [8]. However, inclusion of nanofillers within polymers does not result into electrical properties as high as their metallic filler competitors such as Copper, Silver, and Aluminum $[8,16]$. Therefore, in order to evade from the negative impacts resulting from high filler contents, a combination of different conductive fillers with different geometries, properties, and contents should be investigated. Combination of fillers leads to construction of improved conductive networks through the whole structure. Furthermore, since the formed morphological structure within the conductive polymeric composites resulting from the processing parameters defines the behavior of the products effectively, construction of a holistic numerical, experimental, and manufacturing investigation is necessary to achieve a

\footnotetext{
* Corresponding author.

E-mail address: sadora@dtu.dk (S. Doagou-Rad).
} 


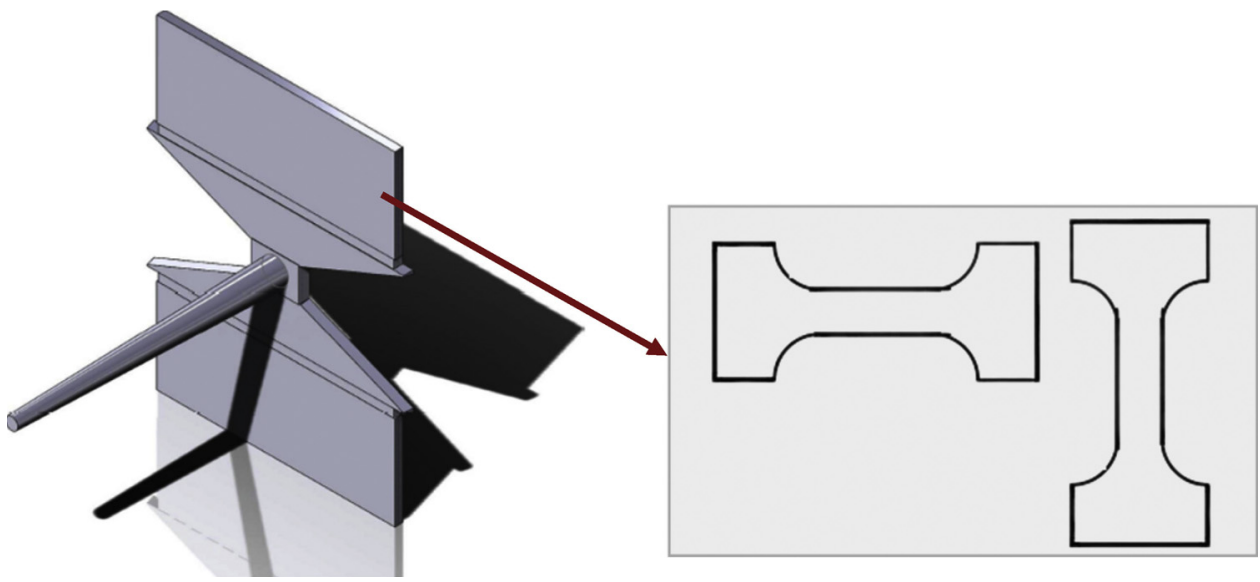

Fig. 1. The geometry of the produced composite specimens.

Table 1

Thermal properties of the produced specimens.

\begin{tabular}{llll}
\hline Sample & Temperature $\left({ }^{\circ} \mathrm{C}\right)$ & $\begin{array}{l}\text { Specific heat }(\mathrm{J} / \\
\left.\mathrm{g}{ }^{\circ} \mathrm{C}\right)\end{array}$ & $\begin{array}{l}\text { Thermal conductivity } \\
\left(\mathrm{W} / \mathrm{m}{ }^{\circ} \mathrm{C}\right)\end{array}$ \\
\hline PA 12 & 25 & 2.149 & $0.37 \pm 0.01$ \\
& 50 & 2.453 & $0.36 \pm 0.02$ \\
& 100 & 2.926 & $0.34 \pm 0.02$ \\
PA 12 & 140 & 3.364 & $0.34 \pm 0.03$ \\
+4 vol. \% CNT & 50 & 1.93 & $0.42 \pm 0.03$ \\
& 100 & 1.99 & $0.41 \pm 0.02$ \\
PA 12 & 140 & 2.51 & $0.41 \pm 0.02$ \\
+30 vol. \% Cu & 25 & 2.98 & $0.39 \pm 0.03$ \\
& 50 & 0.72 & $1.38 \pm 0.03$ \\
PA 12 & 100 & 0.794 & $1.26 \pm 0.05$ \\
+30 vol. \% Cu & 50 & 0.916 & $0.93 \pm 0.06$ \\
+2 vol. \% CNT & 100 & 1.042 & $0.84 \pm 0.07$ \\
& 140 & 0.69 & $1.69 \pm 0.11$ \\
PA 12 & 25 & 0.74 & $1.67 \pm 0.13$ \\
+30 vol. \% Cu & 50 & 0.86 & $1.43 \pm 0.14$ \\
+4 vol. \% CNT & 100 & 0.94 & $1.21 \pm 0.08$ \\
& 140 & 0.62 & $1.85 \pm 0.15$ \\
& & 0.70 & $1.68 \pm 0.11$ \\
\hline & 0.82 & $1.49 \pm 0.07$ \\
& & 0.92 & $1.39 \pm 0.10$ \\
\hline
\end{tabular}

functionally improved components [2,17].

This paper investigates production and properties of the injection molded Polyamide 12 based composites reinforced with micro and nano fillers. Micro copper fibers and carbon nanotubes as the bestknown conductive materials are considered in the design and production to achieve the desired multifunctional properties in the composites. The evolution of features such as electrical, thermal, mechanical, surface, etc. as the functional of manufacturing and filler contents are discussed. Moreover, the involved mechanisms in the property variations are investigated through optical and scanning electron studies in combination with the injection molding simulations.

\section{Experiments}

\subsection{Materials and manufacturing}

The incorporated carbon nanotubes in this study were catalytic chemical vapor deposition produced thin MWCNTs (NC $700{ }^{\mathrm{TM}}$ ) by Nanocyl SA, Belgium, with the average dimeter of $10.4 \mathrm{~nm}$ [18]. Electron mobility in carbon nanotube layers at room temperature could be as high as $2 \times 10^{5} \mathrm{~cm}^{2} / \mathrm{V}$ s leading to the highest known electrical conductivity at room temperature as high as $10^{8} \mathrm{~S} / \mathrm{m}$ [19-21]. The presence of the unlocalized electrons on the graphene surface leads to the exceptional electrical conductivity in the graphene plane. The powder conductivity of the used nanofillers was $10^{5} \mathrm{~S} / \mathrm{m}$. In addition, the used metallic micro fibers were Cu99 copper fibers (STAX, Germany) with the average diameter and length of $45 \mu \mathrm{m}$ and $700 \mu \mathrm{m}$, respectively. The used metallic fibers showed excellent electrical conductivity values as $5.9 \times 10^{7} \mathrm{~S} / \mathrm{m}$. A polyamide 12 (PA12) was also selected as the base polymeric matrix in the produced composites $\left(\mathrm{T}_{\mathrm{g}}=49.1^{\circ} \mathrm{C}\right)$.

PA 12 based composite batches with different contents of micro and nanofillers were compounded between 215 and $240{ }^{\circ} \mathrm{C}$ To perform the melt mixing process a Twin Screw Extruder (Brabender TSE 20/40; Screw length (L : D) 40) was selected. Injection molding of the composite specimens was performed on an Arburg Allrounder 420C (Arburg, Germany) following the instructions of ISO 294-1. The pelletized compounded composites were injected at the nozzle temperature of $245^{\circ} \mathrm{C}$, injection speed of $55 \mathrm{~mm} / \mathrm{s}$, and holding pressure of $55 \mathrm{bar}$. The geometry of the produced parts is illustrated in Fig. 1.

Table 2

Mechanical properties of the produced specimens.

\begin{tabular}{|c|c|c|c|c|}
\hline & Sample & Elastic modulus(GPa) & Tensile strength (yield)(MPa) & Elongation at brek (\%) \\
\hline \multirow[t]{5}{*}{ Transverse } & PA 12 & $1.24 \pm 0.02$ & $35 \pm 1.3$ & $220 \pm 7$ \\
\hline & PA $12+4$ vol. $\%$ CNT & $1.46 \pm 0.03$ & $43 \pm 1.1$ & $80 \pm 3.2$ \\
\hline & PA $12+30$ vol. $\% \mathrm{Cu}$ & $3.2 \pm 0.05$ & $27 \pm 0.3$ & $5.1 \pm 0.3$ \\
\hline & PA $12+30$ vol. $\% \mathrm{Cu}+2$ vol. $\% \mathrm{CNT}$ & $3.3 \pm 0.08$ & $31 \pm 1.7$ & $12 \pm 0.9$ \\
\hline & PA $12+30$ vol. $\% \mathrm{Cu}+4$ vol. $\% \mathrm{CNT}$ & $3.5 \pm 0.08$ & $32 \pm 1.4$ & $7.8 \pm 0.8$ \\
\hline \multirow[t]{5}{*}{ Longitudinal } & PA 12 & $1.28 \pm 0.01$ & $35 \pm 1.1$ & $230 \pm 9.7$ \\
\hline & PA $12+4$ vol. $\%$ CNT & $1.66 \pm 0.01$ & $45 \pm 1.2$ & $83 \pm 4.4$ \\
\hline & PA $12+30$ vol. $\% \mathrm{Cu}$ & $3.5 \pm 0.04$ & $29 \pm 0.2$ & $6.2 \pm 2.1$ \\
\hline & PA $12+30$ vol. $\% \mathrm{Cu}+2$ vol. $\% \mathrm{CNT}$ & $4.1 \pm 0.06$ & $32 \pm 1.6$ & $13.3 \pm 1.7$ \\
\hline & PA $12+30$ vol. $\% \mathrm{Cu}+4$ vol. $\% \mathrm{CNT}$ & $4.3 \pm 0.06$ & $34 \pm 1.9$ & $9.2 \pm 0.7$ \\
\hline
\end{tabular}




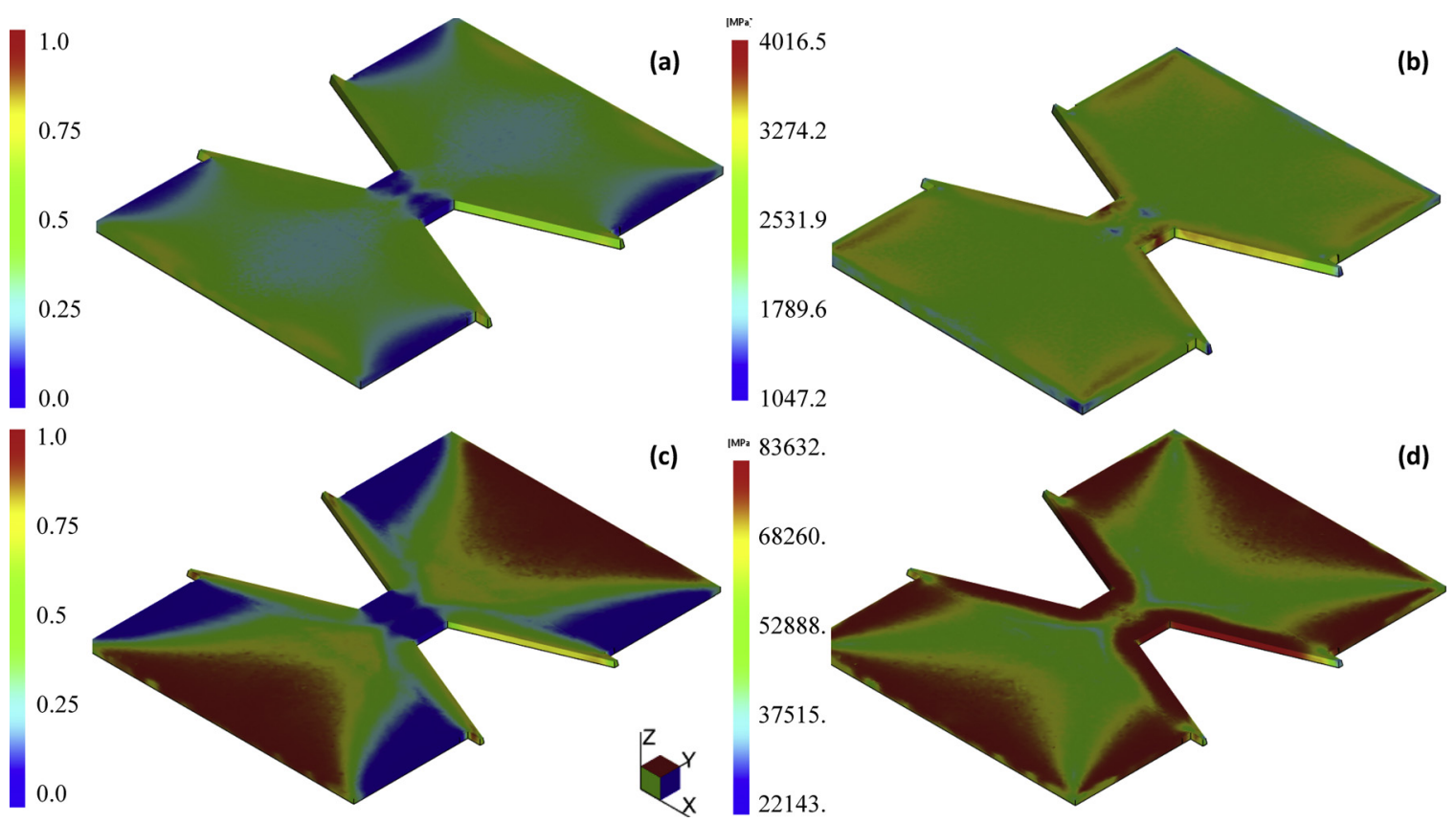

Fig. 2. Mid-plane tensile strength and fibre orientation distributions in principal (x) direction of (a), (b) nanocomposites, and (c), (d) hybrid composites.
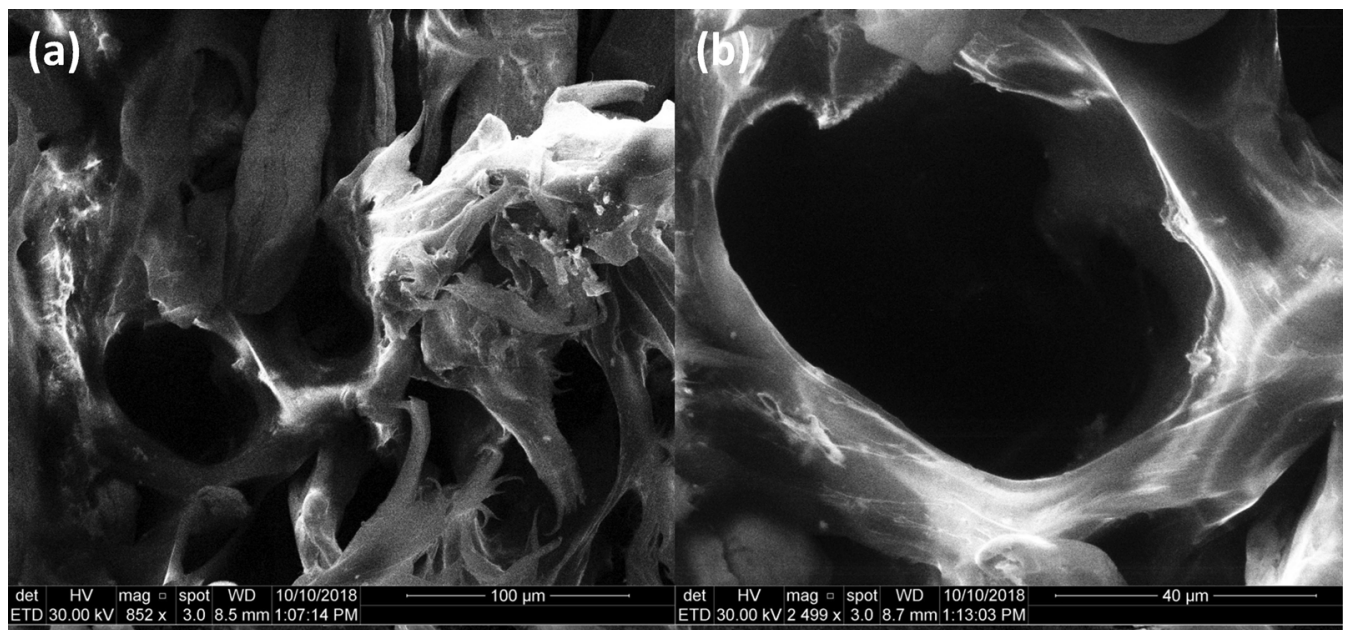

det
EV mag

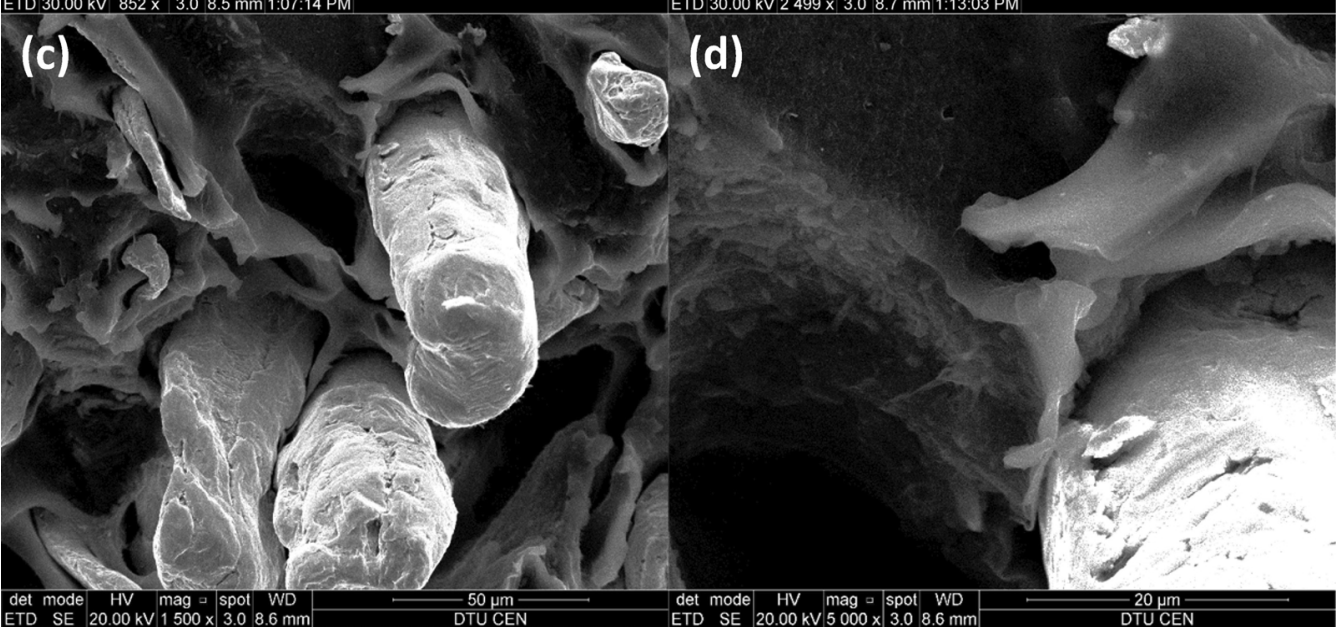

Fig. 3. The pull-out mechanism of copper fibers and the surface area of the holes in (a), (b) Copper filled composites, and (c), (d) PA $12+30$ vol. $\% \mathrm{Cu}+2$ vol. $\%$ CNT hybrid composites. 


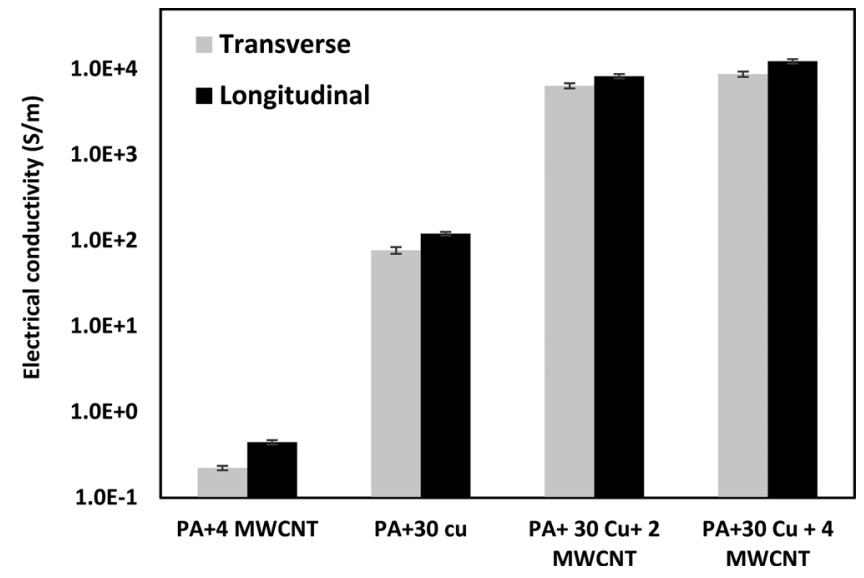

Fig. 4. Electrical conductivity of the produced specimens.

\subsection{Characterization}

The mechanical properties of the injection-molded specimens were characterized using uniaxial tensile experiments using a MTS 858, USA, according to ASTM D1708. The electrical conductivity experiments were performed on rectangular specimens $(20 \times 5 \times 1.5 \mathrm{~mm})$. Volume electrical resistivity was measured at room temperature using two copper electrodes contacting the two ends of the test specimen under constant pressure using a Hewlett Packard multimeter, US. In order to ensure the effective contact between the electrodes and the specimen surfaces, the contacting areas were sanded. Conductive carbon tapes were also placed between the contacts. In addition, a constant pressure (40-50 N) was applied from the holding screw.

In order to attain the required properties for the simulations, the thermal diffusivity of the specimens were determined using laser flash experiments using a LFA 1000 Laser Flash Apparatus. In addition, melt shear viscosity investigations were performed using a Discovery HR-2 (TA Instruments, USA). The oscillatory shear measurements were performed on $25 \mathrm{~mm}$ disc-shape polymeric specimens under nitrogen atmosphere with $1.0 \mathrm{~mm}$ gap between the plates. The capillary rheometry and PVT characterizations were conducted using a Göttfert WerkstoffPrüfmaschinen GmbH Rheograph 25. The optical microscopy studies was performed using a LEXT (Olympus, Japan). Furthermore, in order to study the fracture and involved mechanism in electrical conductivity scanning electron microscopy (SEM) (Quanta FEG 200 ESEM) was employed on the fractured surfaces of the nanocomposites. In order to characterize the melting behavior and specific heat of the produced specimens, nonisothermal thermal studies were conducted on a Discovery DSC (TA instruments). A sample of $4-6 \mathrm{mg}$ of the nanocomposites was cut from the middle section of the injection molded specimens, and placed in sealed aluminum pans. Differential scanning calorimetry (DSC) experiments were performed under Argon atmosphere in the temperature range of $-5{ }^{\circ} \mathrm{C}$ to $180{ }^{\circ} \mathrm{C}$ with the rate of $10^{\circ} \mathrm{C} / \mathrm{min}$.

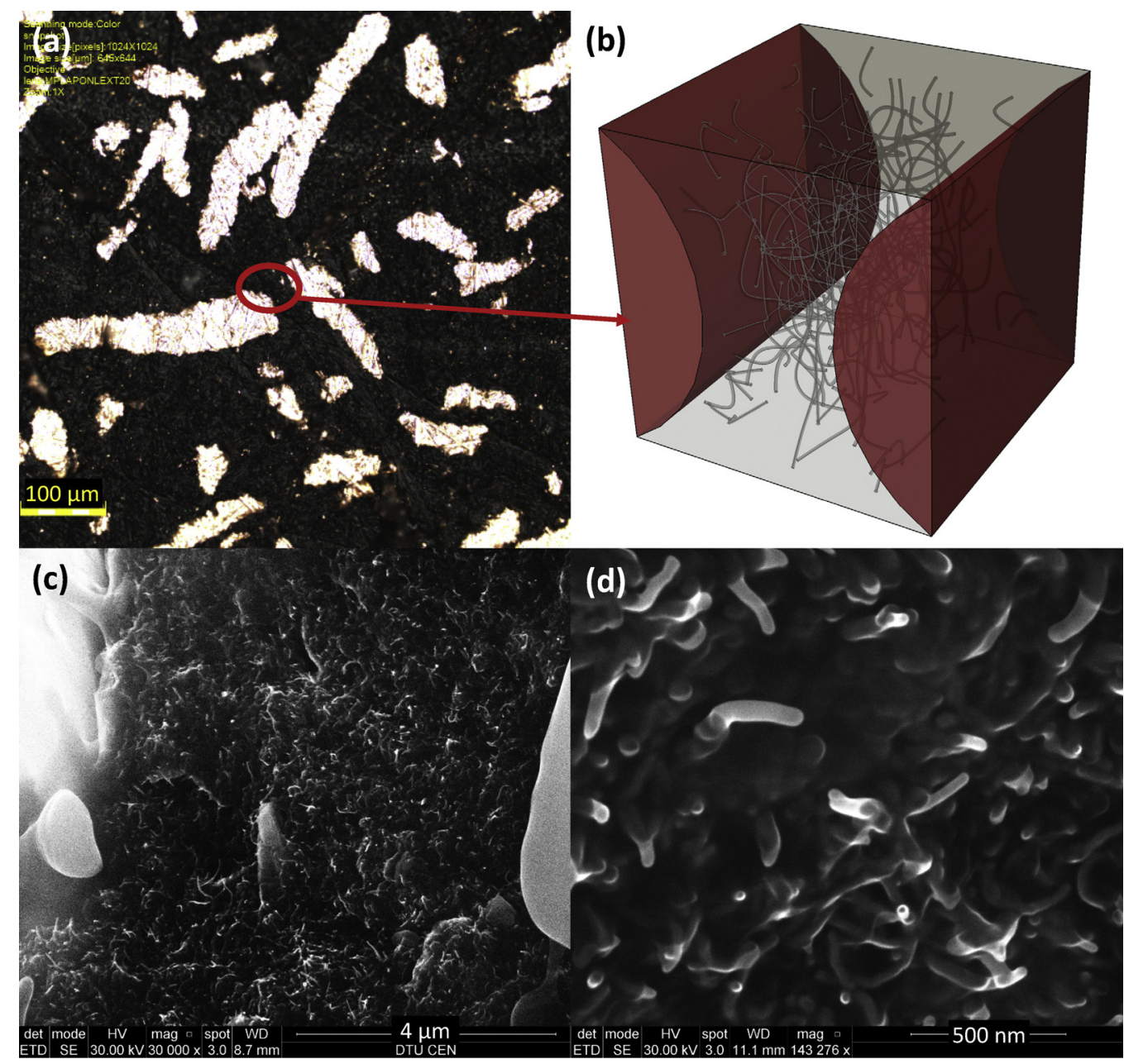

Fig. 5. (a) Optical images of the fibre reinforced composite and the insulating micro gaps between the fibers, (b) the filled gaps with conductive nanofillers. (c) The SEM micrographs of the gap area between the two adjacent ( $5 \mu \mathrm{m}$ distance) copper fibers, in PA $12+30$ vol. \% Cu +2 vol. $\%$ CNT composites and (d) and the bridging mechanisms by carbonic nanofillers. 

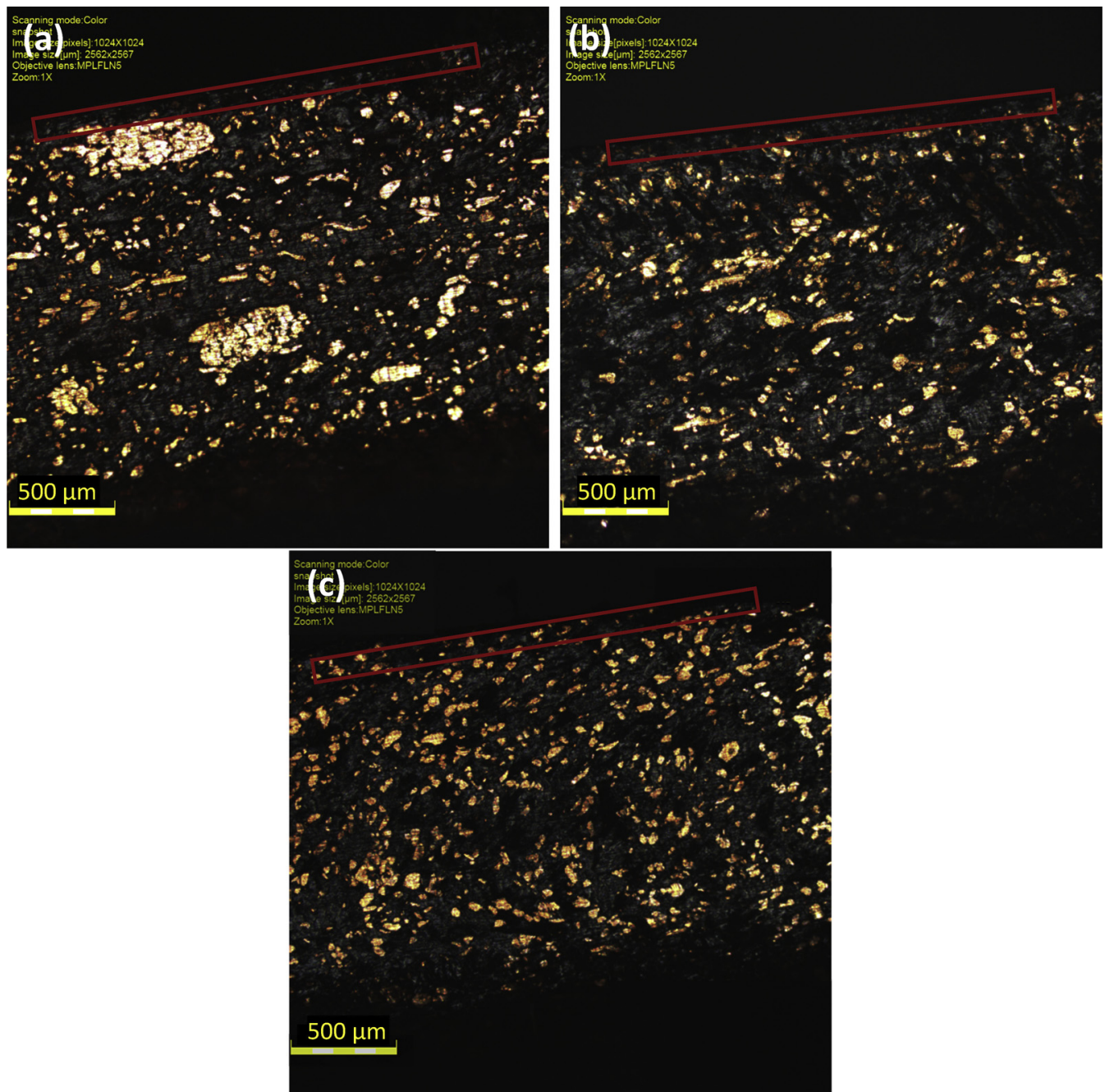

Fig. 6. Cross section of the composites along the thickness: (a) PA $12+30$ vol. $\% \mathrm{Cu}$, (b) PA $12+30$ vol. $\% \mathrm{Cu}+2$ vol. $\% \mathrm{CNT}$ and (c) PA $12+30$ vol. $\% \mathrm{Cu}+4$ vol. $\%$ CNT.

In addition, Autodesk Moldflow simulations were performed according to the performed characterizations on the compounded batches and the injection molding machine parameters.

\section{Results and discussions}

\subsection{Thermal properties}

Table. 1 presents the thermal behavior of the produced specimens. As it can be noticed from the table, while the incorporation of conductive fillers decreased the specific heat values, the thermal conductivity values increased significantly. In fact, the hybrid composites containing both copper micro fillers and carbon nanotubes showed thermal conductivities four times higher than their base polymer. Inclusion of the two different fillers led to enhancement of thermal conductivities additionally. The involved mechanisms in thermal conductivity of the hybrid composites are intricate. In fact, the final thermal conductivity of polymeric composites is determined by the least thermal conductivity among the constituents [22]. Comparing to the thermal conductivity of Copper ( $400 \mathrm{~W} / \mathrm{m} \mathrm{K}$ ), structurally perfect carbon nanofiller could show very high thermal conductivities in the range of $4000-6000 \mathrm{~W} / \mathrm{m} \mathrm{K}$. However, industrially produced nanofillers based on the level of defects and number of layers show diminished conductivity values. In fact, while the heat is mostly transformed by phonons in graphene layers, the heat transfer mechanism in the metallic fillers is controlled by electrons. Combination of the parameters such as the short bond length between carbon atoms, the periodicity of the structures, and the delocalized electrons leads to the enhanced phonon propagation through graphene layers in carbon nanotubes. As the atoms in the composite structure are exposed to a heat source, they start to vibrate. These vibrations with regard to the compact structure of the reinforcements are passed to the neighboring atoms [23]. However, as the temperature rose, the average distance between the phases increased. Therefore, the chances of direct contact between fillers in a homogenous dispersion are decreased. The elevated motion of polymer chains also reduced the stiffness of the structure and the atom vibration effects leading to longer distances for the phonon transport and lower thermal conductivities.

Moreover, it could be noticed that the specific heats of the composites are less than the neat PA12. In fact, the smaller contents of polymers within the structure if composites lead to lower values of specific heats among the produced composites. As the included polyamide reflects the highest specific heat properties among the constituents (compared to specific heats of copper and nanotubes are around 0.3 and 0.7 , respectively), its reduction, would result into the decrease of the specific heats of the composites.

The importance of the observed synergic effect as the result of hybridization is more pronounced when the values is compared with metal filled composites. The traditional composites should contain more than $50 \mathrm{vol}$. \% of conductive fillers to reach the achieved 

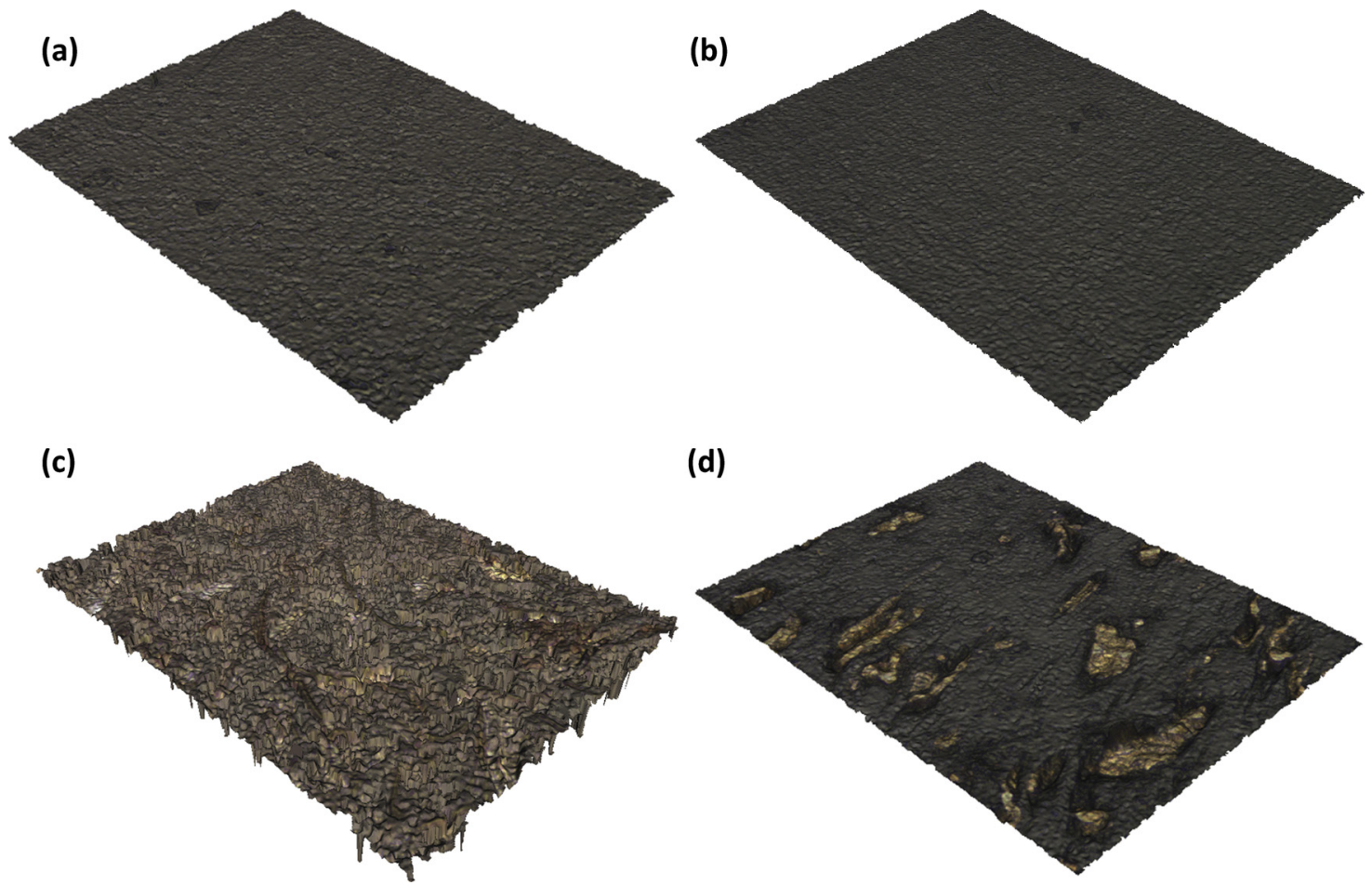

Fig. 7. Optical images of the surface state in (a) neat PA12, (b) PA12 PA 4 vol. $\%$ CNT, (c) PA $12+30$ vol. $\%$ Cu, (d) PA $12+30$ vol. $\%$ Cu +4 vol. $\%$ CNT.

conductivities [24]. Therefore, the hybridization led to high conductivities while the weight and costs of the specimens reduced significantly.

\subsection{Mechanical properties}

In order to understand the produced composites and their applications, their mechanical properties were investigated (see Table 2). Carbon nanotubes are among the strongest known materials. Benefiting from strong $\mathrm{sp}^{2}$ interactions in their structure, they show higher stiffness and tensile strengths than diamond. Strong interactions between the carbon atoms within the unique atomistic structure of carbon nanotubes and graphene with shorter carbon-carbon length than diamond make them strong and stable under deformation. However, while their aspect ratios provide larger interfacial regions leading to enhancement of the properties, their processing is challenging. In fact, achieving dispersed or aligned nanofillers requires effective prior investigations $[8,9,25]$. Results showed that incorporation of 4 vol. \% carbon nanotubes lead to 32 and $28 \%$ enhancement in elastic modulus and tensile strength, respectively. Moreover, while elongation at break decreased significantly, the nanocomposites with elongation at break values more than $80 \%$ show a ductile behavior. Moreover, the combination of copper fibers and carbon nanotubes increased the elastic moduli more than two times compared to the base polymer.

Fig. 2 shows the injection molding simulation results on tensile strength and fibre orientation distribution in nano and hybrid composites. As it can be clearly seen in the figures, the incorporated fillers are more oriented within the hybrid composites. This anisotropy in the final fibre configuration leads to variation of mechanical and electrical properties in the produced composites according to the specimen positioning direction. In order words, the nanofillers in the nanocomposites are mostly distributed randomly; however, in the hybrid composites, the fillers are oriented towards the flow direction. This phenomenon is due to higher aspect ratio of nanofillers and viscosity of the melts in combination with their lower thermal conductivities during the injection molding of the nanocomposites.

Moreover, the mechanical properties in the hybrid composites benefitted from the reinforcement of the polymeric fraction. Fig. 3 shows fractographs of the hybrid composites. The micrographs shows copper fibre pull-out as the main failure mechanisms. As it can be noticed, the pull-out holes are notably rough. This increased roughness is due to better interfacial adhesion between the copper microfibers and the surrounding nanocomposite as the results of the incorporation of the nanotubes. Therefore, more aligned fibers in combination with a strengthened plastic fraction lead to hybrid composites with enhanced mechanical properties.

\subsection{Electrical conductivity}

Fig. 4 shows the influence of conductive fibre incorporation and combination on the electrical properties of the produced composites. Despite the superior electrical properties of carbon nanotubes originating from their hybridization state, the polymeric nanocomposites could usually deliver up to $10 \mathrm{~S} / \mathrm{m}$ [8]. On the other hand, conventional polymeric composites reinforced with metallic fillers could not be processed after certain filler contents levels. Therefore, further electrical conductivity enhancement could not be expected by adding more metal-based fillers. Therefore, nanofillers are incorporated to improve the properties by introducing novel mechanisms.

The idea behind designing hybrid composites originates from the fact that the micro gaps between metallic fillers are filled with an insulating plastic (see Fig. 5(a)). In other words, the network of conductive fillers are compromised in many locations due to the presence of these gaps. The microscopy investigations revealed the dominance of 3-40 $\mu \mathrm{m}$ gaps within the network of the metals. Therefore, incorporation of nanofillers could convert the trapped materials in the gaps between the metallic fillers into conductive mediums resulting into an enhanced electrical network (Fig. 5). Fig. 5(c) and (d) illustrates the constructed bridging mechanism within the hybrid composites. The carbon nanotubes construct a conductive network between themselves. The constructed nano networks enables the electrons to travel between adjacent micro fibers. As the result of combination of nano and micro networks, the electrical conductivities increased by more than two orders of magnitude compared to the metal filled composites [26,27]. It is 
noteworthy to mention that while addition of 2 vol. \% of nanofillers to metal filled systems led to significant improvement in conductivity of the compounds, additional inclusion of nanofillers did not result in similar enhancement. In other words, it seems that a limit for nanofiller inclusion exists wherein the desired networks are constructed within the microstructure and further addition of nanofillers would not lead to effective enhancement. Therefore, the spent cost on the additional nanofiller following the discussed threshold just led to difficulties in mechanical or manufacturing performances.

Moreover, optical microscopy revealed reduction of the fibre depleted frozen layer by addition of nanofillers in the hybrid composites (see Fig. 6). As the nanotubes increased in the composite system, the number of copper fibers increased in the layer adjacent to the surface, which results in a more conductive surface layer and efficient application of the composites without the need for post-processing to remove this skin layer. This phenomenon is due to the flow-induced crystallization and the variation of rheological properties by addition of the nanotubes in the polymeric structure $[8,9]$.

Moreover, incorporation of nanofillers changes the surface characteristics of the produced specimens effectively (see Fig. 7). By addition of the carbon nanotubes in the structure, the surface roughness decreases. The investigation showed that arithmetic average roughness $\left(R_{a}\right)$ decreased from 170 to $100 \mathrm{~nm}$ by addition of nanofillers to the neat polymer. Moreover, $R_{\mathrm{a}}$ decreased $2.5 \mu \mathrm{m}$ to $400 \mathrm{~nm}$ in the produced composites compared to copper filled specimens.

\section{Conclusions}

Production and characterization of novel conductive hybrid composites were investigated. The results showed the effectiveness of combination of the copper micro fibers and carbon nanotubes to achieve multifunctional composites. Hybridization of the fillers led to 220 and $20 \%$ improvement in elastic modulus compared to the neat polymer and the metal filled composite, respectively. Moreover, the electrical and thermal conductivities increased two orders of magnitude and $37 \%$ compared to the metal filled composites, respectively. The bridging mechanism of nanotubes between the micro fillers was recognized as the main mechanism of enhancement of electrical conductivities. Moreover, variation of thermal conductivity and viscosity by addition of nanotubes results in thinner skin layer devoid of copper filler and better surface finish. Therefore, not only the properties are enhanced but also the need for final polishing is eliminated.

\section{Acknowledgements}

The authors are grateful to all their colleagues at the Karlsruhe Institute of Technology. Metin Tülümen, Peter Holzer, Kilian Pursche and Heinz Walter are especially acknowledged for their contributions.

\section{References}

[1] Z.J. Zhao, B.Y. Zhang, Y. Du, Y.W. Hei, X.S. Yi, F.H. Shi, G.J. Xian, MWCNT modified structure-conductive composite and its electromagnetic shielding behavior, Compos. Part B Eng. 130 (2017) 21-27, https://doi.org/10.1016/j. compositesb.2017.07.033.

[2] H. Deng, L. Lin, M. Ji, S. Zhang, M. Yang, Q. Fu, Progress on the morphological control of conductive network in conductive polymer composites and the use as electroactive multifunctional materials, Prog. Polym. Sci. 39 (2014) 627-655.

[3] G.T. Pham, Y.-B. Park, Z. Liang, C. Zhang, B. Wang, Processing and modeling of conductive thermoplastic/carbon nanotube films for strain sensing, Compos. Part B
Eng. 39 (2008) 209-216, https://doi.org/10.1016/j.compositesb.2007.02.024.

[4] A. Islam, H.N. Hansen, N. Giannekas, Quality investigation of miniaturized Moulded Interconnect Devices (MIDs) for hearing aid applications, CIRP Ann, Manuf. Technol. 64 (2015) 539-544, https://doi.org/10.1016/j.cirp.2015.03.003.

[5] S.D. Rad, A. Islam, M. Fuglsang-Philip, A Conceptual Framework for Designing Micro Electrical Connectors for Hearing Aid Instruments, in, (2016) http://orbit. dtu.dk/en/publications/a-conceptual-framework-for-designing-micro-electricalconnectors-for-hearing-aid-instruments(3b9d98de-4194-42f9-85d23dad890d09f8).html.

[6] W. Michaeli, C. Hopmann, J. Fragner, T. Pfefferkorn, Injection molding of conductor paths: integration of functionality by the use of a metal/thermoplastic hybrid material, J. Polym. Eng. 31 (2011) 479-487.

[7] C. Hopmann, J. Fragner, S. Haase, Development of electrically conductive plastic compounds based on filler combinations, J. Plast. Technol. 10 (2014) 49-67.

[8] S. Doagou-Rad, A. Islam, J. Søndergaard Jensen, Correlation of mechanical and electrical properties with processing variables in MWCNT reinforced thermoplastic nanocomposites, J. Compos. Mater. 52 (2018) 3681-3697, https://doi.org/10. 1177/0021998318768390.

[9] S. Doagou-Rad, A. Islam, J.S. Jensen, A. Alnasser, Interaction of nanofillers in injection-molded graphene/carbon nanotube reinforced PA66 hybrid nanocomposites, J. Polym. Eng. 0 (2018), https://doi.org/10.1515/polyeng-2018-0060.

[10] S.H.Ch. Hopmann, J. Fragner, Development of electrically conductive plastic compounds based on filler combinations, J. Plast. Technol. 10 (2014) 49-67.

[12] R. Ravindren, S. Mondal, K. Nath, N.C. Das, Prediction of electrical conductivity, double percolation limit and electromagnetic interference shielding effectiveness of copper nanowire filled flexible polymer blend nanocomposites, Compos. Part B Eng. 164 (2019) 559-569, https://doi.org/10.1016/j.compositesb.2019.01.066.

[13] B.H. Cipriano, A.K. Kota, A.L. Gershon, C.J. Laskowski, T. Kashiwagi, H.A. Bruck, S.R. Raghavan, Conductivity enhancement of carbon nanotube and nanofiber-based polymer nanocomposites by melt annealing, Polymer (Guildf). 49 (2008) 4846-4851.

[14] S.D. Rad, A. Islam, A. Alnasser, Development of metal-graphene-filled hybrid composites: characterization of mechanical, thermal, and electrical properties, J. Compos. Mater. (2018) 2199831881292, , https://doi.org/10.1177/ 0021998318812928.

[15] P.-C. Ma, M.-Y. Liu, H. Zhang, S.-Q. Wang, R. Wang, K. Wang, Y.-K. Wong, B.Z. Tang, S.-H. Hong, K.-W. Paik, J.-K. Kim, Enhanced electrical conductivity of nanocomposites containing hybrid fillers of carbon nanotubes and carbon black, ACS Appl. Mater. Interfaces 1 (2009) 1090-1096, https://doi.org/10.1021/ am9000503.

[16] Y.P. Mamunya, V.V. Davydenko, P. Pissis, E.V. Lebedev, Electrical and thermal conductivity of polymers filled with metal powders, Eur. Polym. J. 38 (2002) 1887-1897, https://doi.org/10.1016/S0014-3057(02)00064-2.

[17] S. Doagou-Rad, J.S. Jensen, A. Islam, L. Mishnaevsky, Multiscale molecular dynamics-FE modeling of polymeric nanocomposites reinforced with carbon nanotubes and graphene, Compos. Struct. 217 (2019) 27-36, https://doi.org/10.1016/j. compstruct.2019.03.017.

[18] B. Mayoral, G. Garrett, T. McNally, Influence of screw profile employed during melt mixing on the micro-scale dispersion of MWCNTs in poly(propylene), Macromol. Mater. Eng. 299 (2014) 748-756, https://doi.org/10.1002/mame.201300172.

[19] A. Akturk, N. Goldsman, Electron transport and full-band electron-phonon interactions in graphene, J. Appl. Phys. 103 (2008) 53702.

[20] K.S. Novoselov, A.K. Geim, Sv. Morozov, D. Jiang, Mi. Katsnelson, Iv. Grigorieva, Sv. Dubonos, A.A. Firsov, Two-dimensional gas of massless Dirac fermions in graphene, Nature. 438 (2005) 197.

[21] T.W. Ebbesen, H.J. Lezec, H. Hiura, J.W. Bennett, H.F. Ghaemi, T. Thio, Electrical conductivity of individual carbon nanotubes, Nature. 382 (1996) 54, https://doi. org $/ 10.1038 / 382054 \mathrm{a} 0$

[22] N. Burger, A. Laachachi, M. Ferriol, M. Lutz, V. Toniazzo, D. Ruch, Review of thermal conductivity in composites: mechanisms, parameters and theory, Prog. Polym. Sci. 61 (2016) 1-28.

[23] A. Li, C. Zhang, Y.-F. Zhang, Thermal conductivity of graphene-polymer composites: mechanisms, properties, and applications, Polymers (Basel). 9 (2017) 437.

[24] G. Wypych, 5 - PHYSICAL PROPERTIES OF FILLERS AND FILLED MATERIALS BT Handbook of Fillers (Fourth Edition), ChemTec Publishing, 2016, pp. 303-371, https://doi.org/10.1016/B978-1-895198-91-1.50007-5.

[25] S. Doagou-Rad, A. Islam, J.S. Jensen, Influence of processing conditions on the mechanical behavior of MWCNT reinforced thermoplastic nanocomposites, Procedia Cirp 66 (2017) 131-136, https://doi.org/10.1016/j.procir.2017.03.362.

[26] W. Fang, H.W. Jang, S.N. Leung, Evaluation and modelling of electrically conductive polymer nanocomposites with carbon nanotube networks, Compos. Part B Eng. 83 (2015) 184-193, https://doi.org/10.1016/j.compositesb.2015.08.047.

[27] W. Bauhofer, J.Z. Kovacs, A review and analysis of electrical percolation in carbon nanotube polymer composites, Compos. Sci. Technol. 69 (2009) 1486-1498, https://doi.org/10.1016/j.compscitech.2008.06.018. 